\title{
Effect of wood species, digester conditions, and defibrator disc distance on wettability of fiberboard
}

\author{
Nadir Ayrilmis ${ }^{1} \cdot$ Jan Thore Benthien $^{2} \cdot$ Martin Ohlmeyer $^{2}$
}

Received: 14 November 2016 / Accepted: 17 February 2017 / Published online: 20 March 2017

(C) The Japan Wood Research Society 2017

\begin{abstract}
Wettability of medium density fiberboard (MDF) surface affects paint or adhesive application and is, thus, of importance in the course of furniture manufacturing. This study investigated the effects of wood species, digester conditions and defibrator disc distance on the wettability properties. It was found that the wettability of the MDF significantly decreased with increasing the defibrator disc distance and increased with the increment in the severity of the digestion conditions. The highest wettability was found for samples made of beech wood having an average contact angle value of $74.5^{\circ}$, followed by poplar $\operatorname{wood}\left(76.5^{\circ}\right)$, birch wood $\left(79.7^{\circ}\right)$, the mixture $(1: 1)$ of scots pine and beech wood $\left(82.9^{\circ}\right)$, and scots pine wood $\left(86.4^{\circ}\right)$, respectively.
\end{abstract}

Keywords Digester - Wettability $\cdot$ Fiberboard $\cdot$ Defibrator disc distance $\cdot$ Wood fiber

Nadir Ayrilmis

nadiray@istanbul.edu.tr

Jan Thore Benthien

jan.benthien@thuenen.de

Martin Ohlmeyer

martin.ohlmeyer@thuenen.de

1 Department of Wood Mechanics and Technology,

Forestry Faculty, Istanbul University, Bahcekoy, Sariyer, 34473 Istanbul, Turkey

2 Thünen-Institut für Holzforschung, Thünen Institute of Wood Research, Leuschnerstr. 91c, 21031 Hamburg, Germany

\section{Introduction}

Medium density fiberboard (MDF) is one of the most commonly used wood-based panels in furniture industry. Finishing coat of MDF is mainly dependent upon the properties of the raw materials, such as wood species, fiber characteristics, and manufacturing parameters. For the direct painting or adhesive application, the surfaces of MDF have to be smooth, stable, and low absorbent. In the coating technology, only surface layer of the MDF is coated with the water- or solvent-based paints. Similarly, UV-cured powder coating technology is a rapidly growing segment of the coatings industry and MDF industry.

The performance of the direct painting, powder coating, or adhesive application is directly related to the surface wettability of the MDF panel [1]. Wettability is defined as a surface condition that determines the degree of wetting and spreading a liquid on the surface, respectively its repellency and non-spread on the surface [2,3]. Wettability is crucial for effective adhesion in wood bonding and important to determine the adhesive and coating properties of wood and wood-based composite surfaces [3-5]. The wettability of the material surfaces can be measured using contact angle method, which is commonly used to determine surface characteristics of wood and wood-based composites.

The defibration process is one of the significant parameters in the production of dry-processed fiberboard. The parameters of the digester conditions, such as press temperature, time, pressure, and defibrator disc distance, significantly affect the wood fiber properties [6-8]. In the MDF manufacture, digesting and refining conditions play important function to produce fibers of target quality. These manufacturing conditions affect the physical and mechanical properties of the MDF panel. In a previous study, Benthien et al. [7] reported that digester and defibration conditions, 
as well as raw material properties affect wood fiber characteristics and thereby the physical and mechanical properties of MDF. It was concluded that wood species, digester conditions, and grinding disc distance are the most influential parameters on the fiber quality.

Although the effect of digester conditions, defibrator disc distance, and tree species on the dimensional stability and mechanical properties of MDF used in this study has been investigated by Benthien et al. [6], the wettability of the MDF panels has not determined. Based on the extensive literature search, there has not been any research on the effect of digester conditions and defibrator disc distance on the wettability of MDF. In this study, the effect of digester conditions, defibrator disc distance, and wood species on the wettability of MDF was investigated.

\section{Materials and methods}

\section{Wood fibers}

Four wood species, scots pine (Pinus sylvestris), beech (Fagus sylvatica), birch (Betula spp.), and poplar (Populous spp.), as well as a pine-beech-mixture $(50 / 50 \mathrm{wt})$, were used in the production of MDF panels. The wood fibers were produced applying the laboratory refiner of the Institut für Holztechnologie Dresden GmbH (IHD) (Dresden, Germany), without adding any additives or resin in the flash tube dryer (blow-line).

Three series of wood fibers were produced in the experiments. In the first series, the wood fibers were produced from different wood species. In the second series, the wood fibers were produced at different digester conditions. In the third series, the wood fibers were produced at different defibrator disc distances. Typical images of fibers produced from scots pine fibers produced at different defibrator disc distances are presented in Fig. 1. The experimental design is given in Table 1.

\section{Resin}

Liquid urea-formaldehyde (UF) resin (Kaurit 350, BASF, Ludwigshafen, Germany) was used as an adhesive in the manufacture of experimental MDF panels. Ammonium nitrate $\left(\mathrm{NH}_{4} \mathrm{NO}_{3}\right)$ solution with $40 \%$ solid content was used as a hardener for the UF resin.

\section{Preparation of MDF panels}

The UF resin content was 12 wt $\%$ based on dry fiber mass and $1 \mathrm{wt} \%$ of hardener solid based on the resin solid content was added into the resin. The wood fibers were put into the rotary drum blender equipped with an
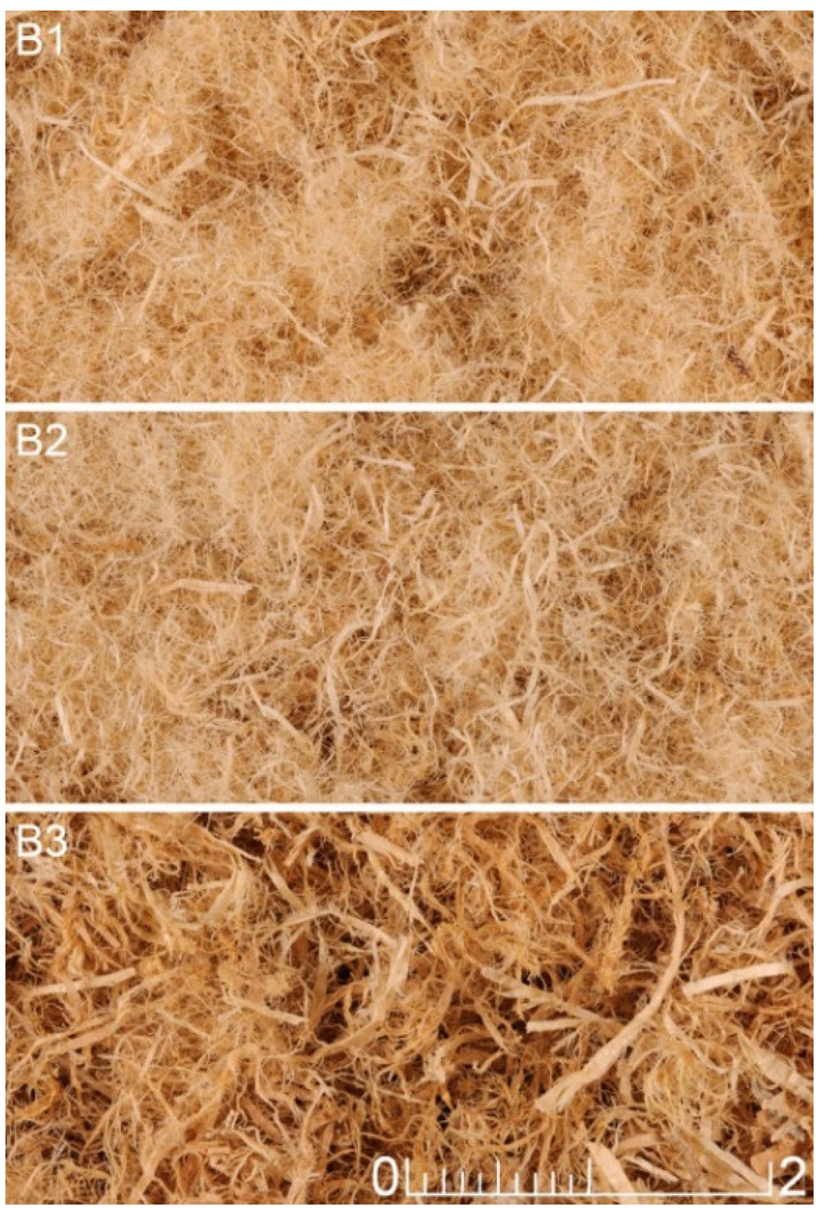

Fig. 1 Typical images of the fibers produced at the defibrator disc distances of $0.06 \mathrm{~mm}(B 1), 0.15 \mathrm{~mm}(B 2)$, and $0.60 \mathrm{~mm}(B 3)$. [on the metric ruler, each individual line represents a millimeter $(\mathrm{mm})]$

air-atomizing spray system and then glued with the UF resin. According to target density of the MDF panel, fibers were weighed and formed into mats on an aluminum caul plate using a $500 \times 500 \mathrm{~mm}$ forming box. A second such plate was laid on the top while both were covered with siliconized paper to prevent adherence between panel and plates. After cold pre-pressing at a specific pressure of $16 \mathrm{~N} / \mathrm{cm}^{2}$ for approximately $10 \mathrm{~min}$, the mats were transferred to a computer-controlled hot press, operated in plate position control mode. Hot pressing temperature, maximal specific pressure, and press time factor were $190^{\circ} \mathrm{C}, 716 \mathrm{~N} / \mathrm{cm}^{2}$, and $12 \mathrm{~s} / \mathrm{mm}$ (totally $192 \mathrm{~s}$ ), respectively. Target panel thickness and density were $16 \mathrm{~mm}$ and $650 \mathrm{~kg} / \mathrm{m}^{3}$, respectively. Three replicate panels were produced from each fiber type. Prior to specimen cutting, the panels were allowed to cool and edges were trimmed. The MDF specimens without sanding were conditioned in a climatic camber having $20^{\circ} \mathrm{C}$ and $65 \%$ relative humidity for 2 weeks before testing. 
Table 1 Experimental design

\begin{tabular}{|c|c|c|c|c|c|}
\hline Experimental series & MDF code & Tree species & $\begin{array}{l}\text { Defibrator disc } \\
\text { distance }(\mathrm{mm})\end{array}$ & Digesting conditions & MDF density $\left(\mathrm{kg} / \mathrm{m}^{3}\right)$ \\
\hline \multirow[t]{6}{*}{ Digester conditions } & A1 & Scots pine & 0.15 & $143^{\circ} \mathrm{C} / 1 \mathrm{~min} / 4 \mathrm{bar}$ & $678(17)^{3}$ \\
\hline & $\mathrm{A} 2$ & Scots pine & 0.15 & $170^{\circ} \mathrm{C} / 1 \mathrm{~min} / 8 \mathrm{bar}$ & $666(24)$ \\
\hline & $\mathrm{A} 3^{1}$ & Scots pine & 0.15 & $170^{\circ} \mathrm{C} / 4 \mathrm{~min} / 8 \mathrm{bar}$ & $661(22)$ \\
\hline & A4 & Scots pine & 0.15 & $170^{\circ} \mathrm{C} / 8 \mathrm{~min} / 8 \mathrm{bar}$ & $684(23)$ \\
\hline & A5 & Scots pine & 0.15 & $200^{\circ} \mathrm{C} / 4 \mathrm{~min} / 8 \mathrm{bar}$ & $670(25)$ \\
\hline & A6 & Scots pine & 0.15 & $200^{\circ} \mathrm{C} / 8 \mathrm{~min} / 16 \mathrm{bar}$ & $687(24)$ \\
\hline \multirow[t]{3}{*}{ Defibrator disc distance } & B1 & Scots pine & 0.06 & $170^{\circ} \mathrm{C} / 4 \mathrm{~min} / 8 \mathrm{bar}$ & $653(30)$ \\
\hline & $\mathrm{B} 2^{1}$ & Scots pine & 0.15 & $170^{\circ} \mathrm{C} / 4 \mathrm{~min} / 8 \mathrm{bar}$ & $661(22)$ \\
\hline & B3 & Scots pine & 0.60 & $170^{\circ} \mathrm{C} / 4 \mathrm{~min} / 8$ bar & $681(30)$ \\
\hline \multirow[t]{5}{*}{ Tree species } & $\mathrm{C} 1$ & Beech & 0.15 & $170^{\circ} \mathrm{C} / 4 \mathrm{~min} / 8$ bar & $683(26)$ \\
\hline & $\mathrm{C} 2^{2}$ & Scots pine/beech & 0.15 & $170^{\circ} \mathrm{C} / 4 \mathrm{~min} / 8 \mathrm{bar}$ & $675(22)$ \\
\hline & $\mathrm{C} 3$ & Birch & 0.15 & $170^{\circ} \mathrm{C} / 4 \mathrm{~min} / 8$ bar & $665(23)$ \\
\hline & $\mathrm{C} 4$ & Poplar & 0.15 & $170^{\circ} \mathrm{C} / 4 \mathrm{~min} / 8$ bar & $659(28)$ \\
\hline & $\mathrm{C} 5^{1}$ & Scots pine & 0.15 & $170^{\circ} \mathrm{C} / 4 \mathrm{~min} / 8 \mathrm{bar}$ & $661(22)$ \\
\hline
\end{tabular}

$M D F$ medium density fiberboard

${ }^{1}$ The samples having MDF codes of A3, B2, and C5 are the same specimens

${ }^{2}$ A mixture of scots pine and beech (50/50 by weight)

${ }^{3}$ The values in the parentheses are standard deviations

\section{Determination of wettability}

The wettability of the MDF specimens was measured by the contact angle method known as goniometer method. Contact angle measurements were performed using a CAM 101 optical contact angle meter (KSV Instruments Ltd., Helsinki, Finland), equipped with a video camera, which collected one image per second. Using the sessile drop method, which is the most widely used procedure, the contact angle was determined simply by aligning tangent with the sessile drop profile at the point of contact with the solid surface. An imaging system was used to measure contact angle and droplet shape for the tested surfaces of the samples. After the $5 \mu \mathrm{L}$ droplet of distilled water was placed on the sample surface, contact angles from the images were measured at $1 \mathrm{~s}$ time intervals up to $30 \mathrm{~s}$ total. Ten specimens with a size of $50 \times 50 \times 16 \mathrm{~mm}$ were taken from each panel for contact angle measurements. A total of 60 contact angle measurements, two measurements from each of 30 specimens, were performed for each panel series given in Table 1.

\section{Statistical analysis}

An analysis of variance, ANOVA, was conducted $(p<0.05)$ to evaluate the effect of wood species, digester conditions, and defibrator disc distance on the wettability of the MDF panels. Significant differences between the average values of the MDF types were determined using Duncan's multiple range test.

\section{Results and discussion}

The wettability behaviour of the MDF panels is given in Table 2. Significant differences in the contact angle values of the MDF specimens are shown with different letters based on the statistical analysis results (Duncan's multiple range test). The different letters in the same column given in Table 2 represent statistical differences at 95\% confidence level. In the first serious experiments, increasing severity of the digester conditions significantly improved the wettability (Table 2). For example, the $5 \mathrm{~s}$ contact angle value of the MDF specimens produced from the fibers at the digester condition of $143^{\circ} \mathrm{C} / 1 \mathrm{~min} / 4$ bar was found to be $93.7^{\circ}$, while it was found to be $75.9^{\circ}$ for the digester condition of $200^{\circ} \mathrm{C} / 8 \mathrm{~min} / 16$ bar.

The contact angle of the wood fibers produced at low digestion conditions (MDF types A1 and A2) type was nearly $90^{\circ}$, indicating that water hardly wet the straw material. This means that the raw material without treatment is more hydrophobic.

The contact angle less than $90^{\circ}$ indicates that wetting of the surface is favorable, and the fluid will spread over a large area on the surface [9]. The MDF specimens produced from the fibers of the chips steamed at $143^{\circ} \mathrm{C} / 1 \mathrm{~min} / 4 \mathrm{bar}$ and $170^{\circ} \mathrm{C} / 1 \mathrm{~min} / 8$ bar had poor wettability, which had the 
Table 2 Contact angle values of the MDF specimens

\begin{tabular}{llll}
\hline MDF code & \multicolumn{3}{l}{ Contact angle measuring intervals } \\
\cline { 2 - 4 } & 5 s Degree $\left(^{\circ}\right)$ & $10 \mathrm{~s}$ Degree $\left(^{\circ}\right)$ & $30 \mathrm{~s}$ Degree $\left(^{\circ}\right)$ \\
\hline $\mathrm{A} 1$ & $93.7(4.0) \mathrm{ae}^{3}$ & $88.6(2.7) \mathrm{a}$ & $78.1(2.8)^{4} \mathrm{a}$ \\
$\mathrm{A} 2$ & $90.2(4.8) \mathrm{a}$ & $85.8(4.8) \mathrm{ab}$ & $77.5(3.7) \mathrm{ab}$ \\
$\mathrm{A} 3^{1}$ & $86.4(5.1) \mathrm{d}$ & $85.2(3.1) \mathrm{ab}$ & $78.4(3.9) \mathrm{a}$ \\
$\mathrm{A} 4$ & $82.4(3.7) \mathrm{b}$ & $83.7(2.6) \mathrm{b}$ & $74.7(3.1) \mathrm{b}$ \\
$\mathrm{A} 5$ & $76.1(3.0) \mathrm{cf}$ & $70.2(2.5) \mathrm{ce}$ & $63.4(2.8) \mathrm{ce}$ \\
$\mathrm{A} 6$ & $75.9(2.8) \mathrm{cf}$ & $68.1(3.1) \mathrm{c}$ & $56.9(2.2) \mathrm{df}$ \\
$\mathrm{B} 1$ & $78.6(3.6) \mathrm{c}$ & $71.1(3.7) \mathrm{e}$ & $64.6(3.2) \mathrm{ce}$ \\
$\mathrm{B}{ }^{1}$ & $86.4(5.1) \mathrm{d}$ & $85.2(3.1) \mathrm{ab}$ & $78.4(3.9) \mathrm{a}$ \\
$\mathrm{B} 3$ & $95.2(4.4) \mathrm{e}$ & $86.3(4.2) \mathrm{a}$ & $79.7(4.1) \mathrm{a}$ \\
$\mathrm{C} 1$ & $74.5(5.5) \mathrm{f}$ & $68.5(3.1) \mathrm{c}$ & $55.7(2.4) \mathrm{d}$ \\
$\mathrm{C} 2$ & $82.9(3.9) \mathrm{b}$ & $79.3(3.5) \mathrm{d}$ & $66.1(2.9) \mathrm{c}$ \\
$\mathrm{C} 3$ & $79.7(4.4) \mathrm{c}$ & $72.6(2.6) \mathrm{e}$ & $62.9(3.2) \mathrm{ef}$ \\
$\mathrm{C} 4$ & $76.5(5.5) \mathrm{cf}$ & $70.5(3.1) \mathrm{ce}$ & $59.7(2.4) \mathrm{f}$ \\
$\mathrm{C} 5{ }^{1}$ & $86.4(5.1) \mathrm{d}$ & $85.2(3.1) \mathrm{ab}$ & $78.4(3.9) \mathrm{a}$ \\
\hline
\end{tabular}

$M D F$ medium density fiberboard

${ }^{1}$ The samples having MDF codes of A3, B2 and C5 are the same specimens

${ }^{2}$ Groups with the same letter are not statistically different at a significance level of $\alpha=0.05$

${ }^{3}$ The values in the parentheses are standard deviations

contact angle values were higher than $90^{\circ}$. In a previous study, it was reported that the improvement in the wettability of the lignocellulosic fibers was probably due to the exposed highly reactive hydroxyl groups of the lignocellulosic fiber resulted from increased severity of digester conditions. This will help improve the bonding strength between the lignocellulosic fiber and water-soluble urea UF resin.

The results showed that the hydrophobicity of the fibers increased with increasing severity of the digester conditions, because the contact the angle values of the MDF specimens decreased with increasing temperature, time, and pressure in the digester. The hydrolysis rate of the wood increased as the chips were steamed in the digester with harsh conditions. The extent of lignin removal, the presence of hemicelluloses or other carbohydrate material, and extractives at the fiber surface significantly affects the wettability of the fiber [10]. Under the digestion conditions, most extractives are removed but a residual pitch fraction may remain [11]. Extractives in the walls of wood cell make wood less permeable and negatively affect the wettability [12]. The presence of residual extractives and hydrophobic lignin on the fiber surface can decrease the wettability of wood fiber [10]. It was estimated that the wood chips steamed at low digestion conditions, such as Types A1 and A2 in Table 1, had a lower polar component leading to a higher contact angle with water $[11,13,14]$. The chips steamed in the lower digestion conditions had higher extractive and lignin content as compared to the higher digestion conditions, which resulted in a higher. In a previous study Walinder and Gardner [15] reported that a larger amount of both extractives and lignin in the surface would result in a higher contact angle. The fiber color also became significantly darker with increasing treatment conditions in the digester.

The wettability of the MDF decreased with increasing defibrator disc distance. The contact angle values ( $5 \mathrm{~s}$ ) of the MDF specimens at the $0.06,0.15$, and $0.60 \mathrm{~mm}$ defibrator disc distance were found to be $78.6^{\circ}, 86.4^{\circ}$, and $95.2^{\circ}$, respectively. There were significant differences in the wettability ( $5 \mathrm{~s}$ ) values of the MDF panels produced from the fibers at the defibrator disc distances of the $0.06,0.15$, and $0.60 \mathrm{~mm}$. However, there were no significant differences between 0.15 and $0.60 \mathrm{~mm}$ distances at 10 and $30 \mathrm{~s}$ measurement intervals. Since the $5 \mathrm{~s}$ contact angle value of the MDF panels produced from the fibers at the defibrator disc distances of the $0.60 \mathrm{~mm}$ was above $90^{\circ}$, its wettability was poor as compared to the 0.06 and $0.15 \mathrm{~mm}$ distances. The amount of fine fibers significantly increased with decreasing disc distance (Fig. 1).

At the same digestion conditions and defibrator disc distance, the highest wettability (the lowest contact angle) was found in the MDF specimens produced with the fibers of beech wood, followed by poplar wood, birch wood, scots pine/beech wood, and scots pine wood, respectively. The camera captures of the MDF specimens produced by scots pine wood fibers (MDF type A1) and the specimens produced from beech wood fibers (MDF type $\mathrm{C} 1$ ) are presented in Fig. 2. There was no significant differences in the contact angle values of birch and poplar MDF specimens, while this was not observed for other species. The anatomical and chemical properties of wood significantly affect the morphological characteristics of the fiber surface, which affect the wettability of the wood fiber [16]. Mantanis and Young [10] reported that the separation of the middle-lamella during the pulping process for beech wood should be less of a rupture, since the lignin had less crosslinks and therewith could contribute to a smoother surface roughness. This could partly explain that the MDF panels produced from beech wood fibers had the highest wettability among the MDF types. The results showed that decreasing fiber length positively affected the wettability of the MDF specimens.

\section{Conclusions}

This research work showed that the surface wettability of MDF panels was significantly affected by the digester conditions, defibrator disc distance, and the wood species. The 
Fig. 2 Typical contact angle camera captures of the water droplets on the MDF specimens at $5 \mathrm{~s}$

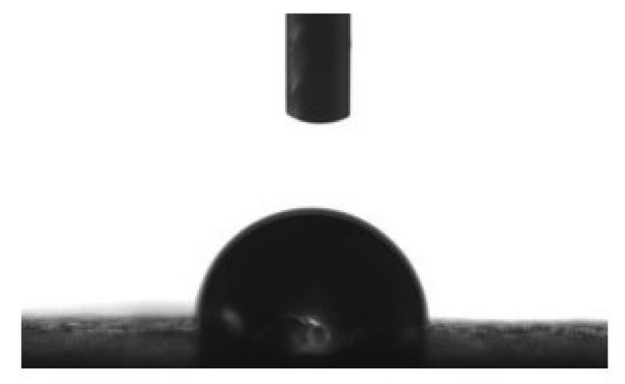

MDF Type Al
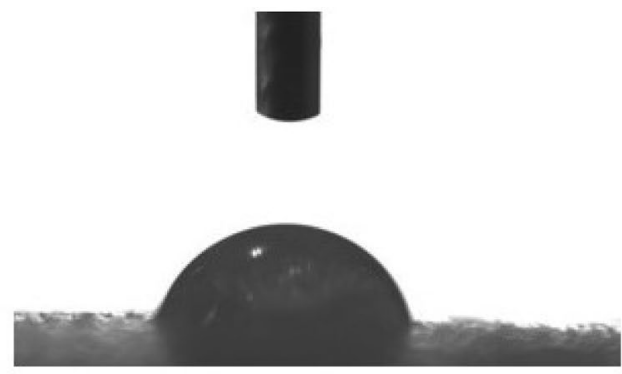

MDF Type Cl wettability of the MDF decreased with increasing the defibrator disc distance. At the same digestion conditions and defibrator disc distance, the highest wettability (the lowest contact angle) was found in the MDF specimens produced with beech wood, followed by poplar wood, birch wood, scots pine/beech wood, and scots pine wood, respectively. The increment in the severity of the digestion conditions improved the wettability of the specimens, which resulted in a decrement in the contact angle values. The better wettability of MDF panels would contribute to the improvement of the bondability between MDF panel and watersoluble UF resin, thus to improved performances of the products. The findings of the present study can be also used by the MDF manufacturers, which produce paintable MDF panel for furniture industry.

\section{References}

1. Good RJ (1992) Contact angle, wetting, and adhesion: a critical review. J Adhes Sci Technol 6:1269-1302

2. Ayrilmis N, Benthien JT, Thoemen H (2012) Effects of formulation variables on surface properties of wood plastic composites. Compos Part B 43:325-331

3. Ayrilmis N, Winandy JE (2009) Effects of post heat treatment on surface characteristics and adhesive bonding performance of medium density fiberboard. Mater Manuf Process 24:594-599

4. Kariz M, Sernek M (2010) Bonding of heat-treated spruce with phenol-formaldehyde adhesive. J Adhes Sci Technol 24:1703-1716
5. Han G, Kawai S, Umemura K, Zhang M, Honda T (2001) Development of high-performance UF-bonded reed and wheat straw medium-density fiberboard. J Wood Sci 47:350-355

6. Deppe HJ, Ernst K (1996) MDF - mitteldichte faserplatte. DRWverlag weinbrenner $\mathrm{GmbH} \& \mathrm{Co}$., Leinfelder-Echterdingen

7. Benthien JT, Bähnisch C, Heldner S, Ohlmeyer M (2014) Effect of fiber size distribution on medium-denstiy fiberboard properties caused by varied steaming time and temperature of defibration process. Wood Fiber Sci 46:175-185

8. Xing C, Deng J, Zhang SY (2007) Effect of thermo-mechanical refining on properties of MDF made from black spruce bark. Wood Sci Technol 41:329-338

9. Erbil HY (2014) The debate on the dependence of apparent contact angles on drop contact area or three-phase contact line: a review. Surf Sci Rep 69:325-365

10. Mantanis GI, Young RA (1997) Wetting of wood. Wood Sci Technol 31:339-353

11. Barnett J, Jeronimidis G (2005) Wood quality and its biological basis. CRC Press, Boca Raton

12. Nguyen T, Johns WE (1979) The effects of aging and extractives on the surface free energy of Douglas-fir and red wood. Wood Sci Technol 13:29-40

13. Hodgson KT, Berg JC (1988) Dynamic wettability properties of single wood pulp fibers and their relationship to absorbency. Wood Fiber Sci 20:3-17

14. Chen C (1970) Effect of extractive removal on adhesion and wettability of some tropical woods. For Prod J 20:36-40

15. Walinder MEP, Gardner DJ (1999) Factors influencing contact angle measurements on wood particles by column wicking. J Adhes Sci Technol 13:1363-1374

16. Wang B, He B, Li J (2010) Study on lignin coverage of masson pine fiber. Bioresources 5:1799-1810 